\title{
GREEN SYNTHESIS, CHARACTERIZATION AND ANTIBACTERIAL STUDIES OF CuO NANOPARTICLES FROM EICHHORNIA CRASSIPES
}

\author{
S. Hemalatha* and M. Makeswari \\ Department of Chemistry, Karpagam Academy of Higher Education, Karpagam University, \\ Coimbatore-641201, Tamilnadu, India \\ *E-mail :hlathacbe@gmail.com
}

\begin{abstract}
Green synthesis of metal and metal oxide nanoparticles using plants is a predominantly focused research area. In the present work, the $\mathrm{CuO}$ nanoparticle synthesis was carried out by a versatile technique from Eichhornia crassipes leaf extract using $\mathrm{NaOH}$. The synthesized particles were characterized with U-V Visible absorption spectra, X-Ray Diffraction analysis (XRD), Fourier Transform infrared spectroscopy (FTIR), Energy Dispersive X-ray spectroscopy (EDX), and Scanning Electron Microscopy (SEM) analysis. The size of the synthesized nanoparticles was obtained to be $20 \pm 2 \mathrm{~nm}$ and the particle shows excellent antibacterial activity for the pathogens like Staphylococcus pneumonia, Streptococcus aureus, and Klebsiella pneumonia.
\end{abstract}

Keywords. $\mathrm{CuO}$ nanoparticles, Eichhornia crassipes, XRD, EDX, antibacterial activity.

(c) RASĀYAN. All rights reserved

\section{INTRODUCTION}

The advances in nanotechnology have led to the great development in various fields including nanoparticles, nano tubes, and nanowire synthesis. ${ }^{1}$ The synthesized nanoparticles have immensely small in size and also have a large surface to volume ratio. ${ }^{1}$ This shows the difference in their physical and chemical properties. ${ }^{2-4}$ Among which metal oxide nanoparticles are of utmost importance because of their extensive application in various fields.

The synthesis of metal oxide nanoparticles using plants is a very economic method when compared to other physical methods and chemical methods. Hence plant mediated synthesis of metal oxide nanoparticles is a field of current importance. ${ }^{5,6}$

Among the various metal oxide nanoparticles synthesized through green route, copper oxide nanoparticles have gained the attention because of its biological and mechanical properties. ${ }^{7} \mathrm{CuO}$ nanoparticles show the important applications as antimicrobials. ${ }^{8-10}$ The $\mathrm{CuO}$ nanoparticle also finds its application in gas sensors, superconductors, solar energy conversion tools etc. ${ }^{11-14}$ Synthesis of $\mathrm{CuO}$ nanoparticles using the extracts, tissues and other parts of plants is an emerging field of extensive application.

Eichhornia crassipes (Water hyacinth) is an aquatic weed plant, which belongs to the family of pontederiaceae. The extensive growth of this weed plant creates enormous problems like eutrophication, depletion of oxygen etc. A proper method of disposal is yet to be found. Green synthesis of nanoparticles using Eichhornia crassipes is gaining importance nowadays which may be a better alternative for its disposal by a constructive mean. ${ }^{15}$

Green synthesis of $\mathrm{CuO}$ nanoparticles from the aqueous extract of Eichhornia crassipes leaves using $\mathrm{NaOH}$, its characterization and its antibacterial activities against pathogenic bacteria were reported in this work.

\section{EXPERIMENTAL}

Synthesis of CuO Nanoparticles using Eichhornia crassipes leaf extract

Fresh leaves of Eichhornia crassipes were collected in polyethene bags from Kuruchi lake, Coimbatore, Tamil Nadu, India. (10 $\left.57^{\prime} 36^{\prime \prime} \mathrm{N}, 77^{\circ} 0^{\prime} 36^{\prime \prime} \mathrm{E}\right)$. It was washed thoroughly with distilled water. About 5 
gm of the leaves were cut and ground finely in a mortar and pestle. It was extracted with $100 \mathrm{ml}$ of distilled water in a conical flask. The extract was heated for about 1 hour and filtered (Whatman 40 filter paper). It was then stored for further use in the refrigerator.

Copper sulfate was used as the precursor. $1 \mathrm{M}$ Copper sulfate solution was prepared and heated for an hour in a water bath. Then it was mixed with the extract under continuous stirring for one hour. Then 2 gms of $\mathrm{NaOH}$ pellets were added and stirred continuously for half an hour. A black precipitate obtained was filtered, washed and dried.

\section{Characterization studies of CuO Nanoparticles}

The optical property of the prepared $\mathrm{CuO}$ nanoparticles was analyzed by UV-Visible [Shimadzu] absorption spectra. Crystallinity and crystal phases were identified with X-Ray Diffraction [PerkinElmer] spectrometer. Functional group analysis was done with FTIR [Shimadzu] Spectrometer. Elemental analysis was done with the Energy Dispersive X-Ray [RONTEC'S EDX system] spectrometer. Particle morphology was analyzed by Scanning Electron Microscope [Model JSM6390LV].

\section{Antibacterial activity of $\mathrm{CuO}$ nanoparticles}

The antibacterial activity of $\mathrm{CuO}$ nanoparticles against bacterial pathogens was determined by a revised Kirby Bauer well diffusion method. ${ }^{16}$ Streptococcus pneumonia, Staphylococcus aureus, and Klebsiella pneumonia were provided by Microbiology Department, Karpagam University, Coimbatore, India. In this analysis, the positive control used was tetracycline. The microbes were cultured in nutrient broth. Then it was incubated at a temperature of $37^{\circ} \mathrm{C}$ for about 12 hours. A 100 Microliter $(\mu \mathrm{L})$ solution of broth microbial culture was prepared which was then blown out on Muller Hinton agar plates. The plates were left undisturbed for about 10 minutes to enhance culture absorption. With a sterile gel puncher, the wells $(5 \mathrm{~mm}$ size $)$ were pierced into the agar. Using a micropipette a 100 Microliter $(\mu \mathrm{L})$ solution $(50 \mu \mathrm{g} / \mathrm{ml}$ and $25 \mu \mathrm{g} / \mathrm{ml})$ of $\mathrm{CuO}$ nanoparticles and 100 Microliter $(\mu \mathrm{L})$ solutions $(10 \mu \mathrm{g} / \mathrm{ml})$ of the positive control (tetracycline) were taken which was then shifted to the wells kept in all plates. The incubation was carried out at a temperature of $37^{\circ} \mathrm{C}$ for about $24 \mathrm{hrs}$. The size of the inhibition zone was quantified. The same analysis was repeated for three replicates. The results of the mean and standard error of the mean were presented.

\section{Optical property analysis by UV-Visible absorption spectroscopy}

Ultra Violet - visible absorption spectra of the prepared $\mathrm{CuO}$ nanoparticles are displayed in the Figure- 1 . The spectra exhibit maximum absorption at $410 \mathrm{~nm}$. The collective oscillation of the free conduction band electrons excited by the incident electromagnetic radiation contributes to the surface plasmon absorption in the $\mathrm{CuO}$ nanoparticles. A maximum Surface plasmon absorption band at $410 \mathrm{~nm}$ specifies the formation of $\mathrm{CuO}$ nanoparticles. ${ }^{17,18}$

\section{XRD analysis}

The pattern of XRD analysis obtained for the prepared $\mathrm{CuO}$ nanoparticles is revealed in Fig.-2. The XRD analysis shows strong peaks at $35^{\circ}$ and $38^{\circ}$ and confirms a single-phase monoclinic structure for the $\mathrm{CuO}$ nanoparticles (JCPDS-41-254) ${ }^{14}$. The broad peaks indicate the small size of the products. The XRD pattern shows no impurity peaks. The size of the $\mathrm{CuO}$ nanoparticles is calculated by applying the DebyeScherer procedure. ${ }^{19}$

$$
D=\frac{0.9 \lambda}{\beta \cos \theta}
$$

Where $\lambda=$ wavelength of $\mathrm{X}$-ray radiation,

$\beta=$ full width at a half maximum of the peaks at the diffracting angle $\theta$.

It is found to be in the average range of 20-22 nm. 
RASĀYAN $J$. Chem.

Vol. 10 | No. 3 |838 - 843 | July - September | 2017

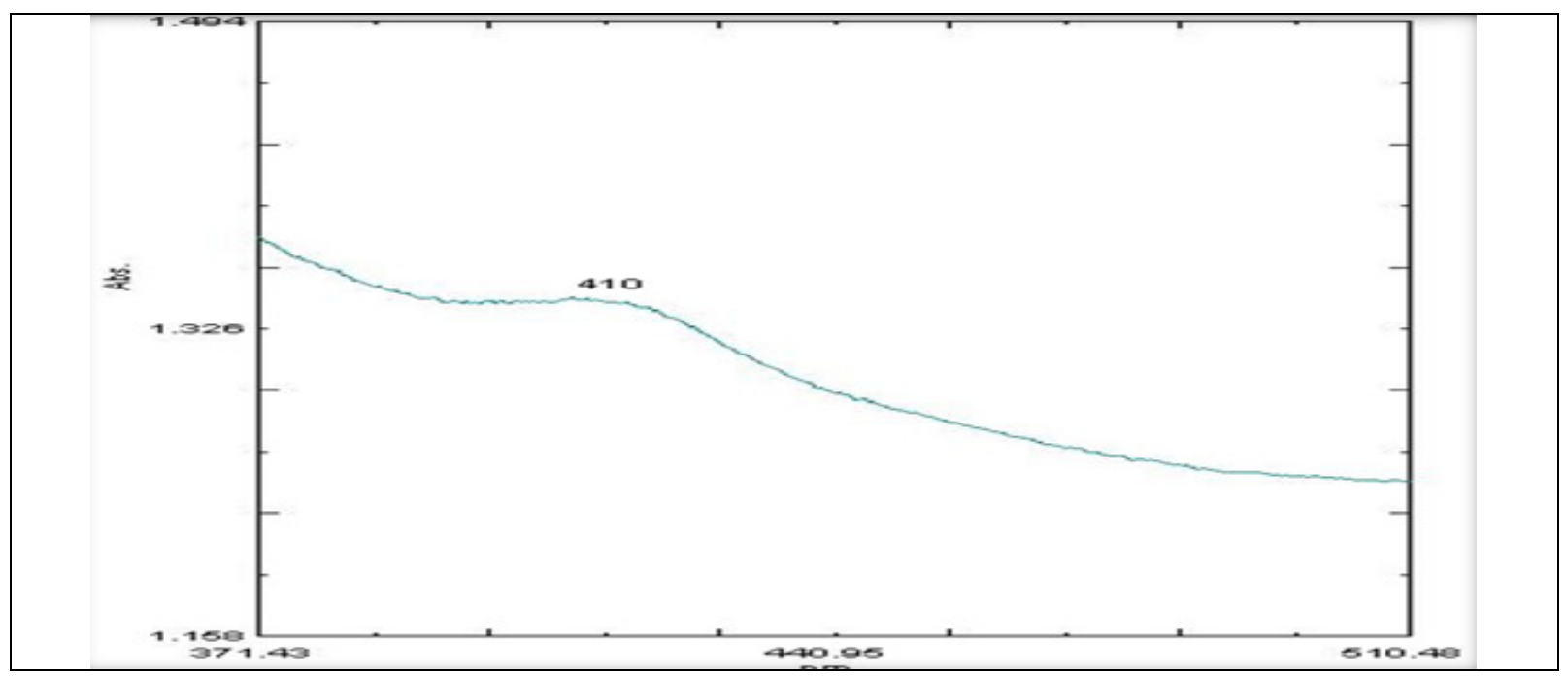

Fig.-1: UV-visible absorption spectra of $\mathrm{CuO}$ nanoparticles

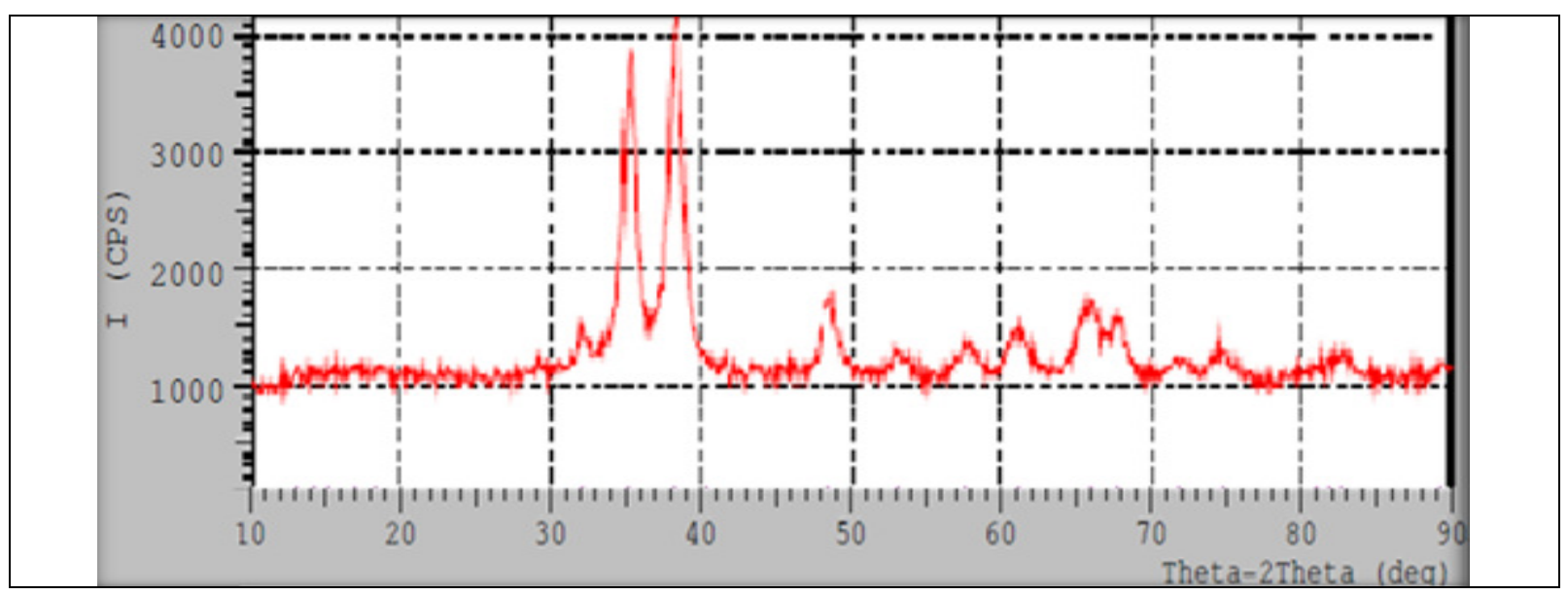

Fig.-2: XRD spectra of $\mathrm{CuO}$ nanoparticles

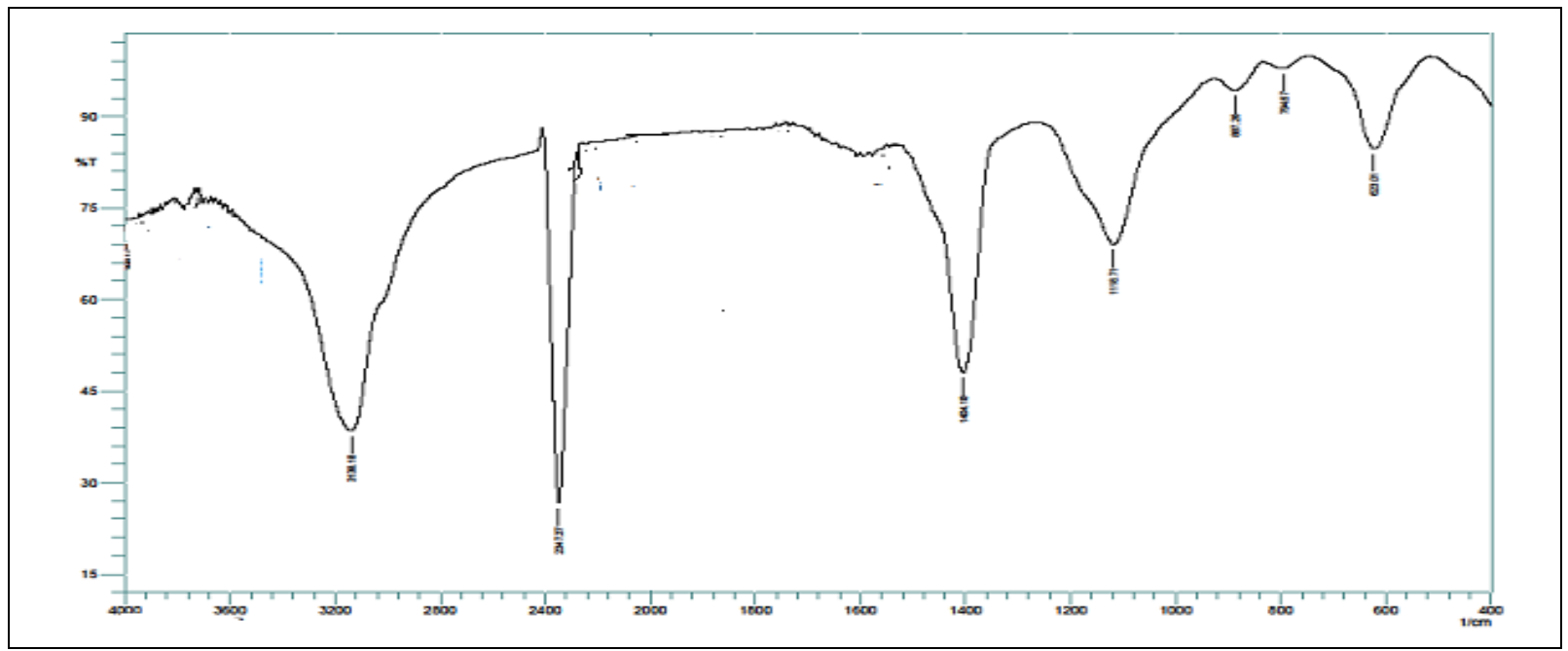

Fig.-3: FTIR spectra of $\mathrm{CuO}$ nanoparticles 


\section{FTIR analysis}

The FTIR spectrum results are shown in the Fig.-3. This helps to know the biomolecules attached to the surface of $\mathrm{CuO}$ nanoparticles. The spectrum displays absorption bands at $3138 \mathrm{~cm}^{-1}$ and $2347 \mathrm{~cm}^{-1}$. This is due to $\mathrm{OH}-$ and $\mathrm{N}-\mathrm{H}$ stretching on the surface of the nanostructured $\mathrm{CuO}$ crystals. The band obtained at $1404 \mathrm{~cm}^{-1}$ specifies C-N stretching and the band at $1118 \mathrm{~cm}^{-1}$ indicates $\mathrm{C}-\mathrm{C}-\mathrm{N}$ bending. The peaks witnessed at $623 \mathrm{~cm}^{-1}, 794 \mathrm{~cm}^{-1}$ and $887 \mathrm{~cm}^{-1}$ expresses the $\mathrm{Cu}-\mathrm{O}$ stretching and indicates the formation of the $\mathrm{CuO}$ nanostructure.

\section{EDX/SEM analysis}

The EDX Spectrum of the synthesized $\mathrm{CuO}$ nanoparticles is given in the Fig.-4. The percentage of elements present is given in the Table-1. The spectra show major peaks for $\mathrm{Cu}$ and $\mathrm{O}$ which confirms the synthesized $\mathrm{CuO}$ nanoparticles. It was also in accord with the synthesis of $\mathrm{CuO}$ nanoparticles from Aloe barbadensis. ${ }^{20}$ The images obtained for SEM analysis is shown in the Fig.-5. From the SEM image, it is observed that the $\mathrm{CuO}$ nanoparticles had a well-defined morphology and are nearly spherical in shape.

Table-1: Percentage of elements from EDX spectra

\begin{tabular}{c|c|c|c|c|c}
\hline Element & App conc & Intensity Corrn & Weight\% & Weight \% Sigma & Atomic\% \\
\hline $\mathrm{O} \mathrm{K}$ & 79.17 & 1.2337 & 26.08 & 0.45 & 49.85 \\
\hline $\mathrm{Na} \mathrm{K}$ & 16.56 & 0.4412 & 15.25 & 0.53 & 20.29 \\
\hline $\mathrm{S} \mathrm{K}$ & 6.66 & 0.7876 & 3.44 & 0.16 & 3.28 \\
\hline $\mathrm{Cu} \mathrm{K}$ & 121.92 & 0.8972 & 55.23 & 0.56 & 26.58 \\
\hline
\end{tabular}

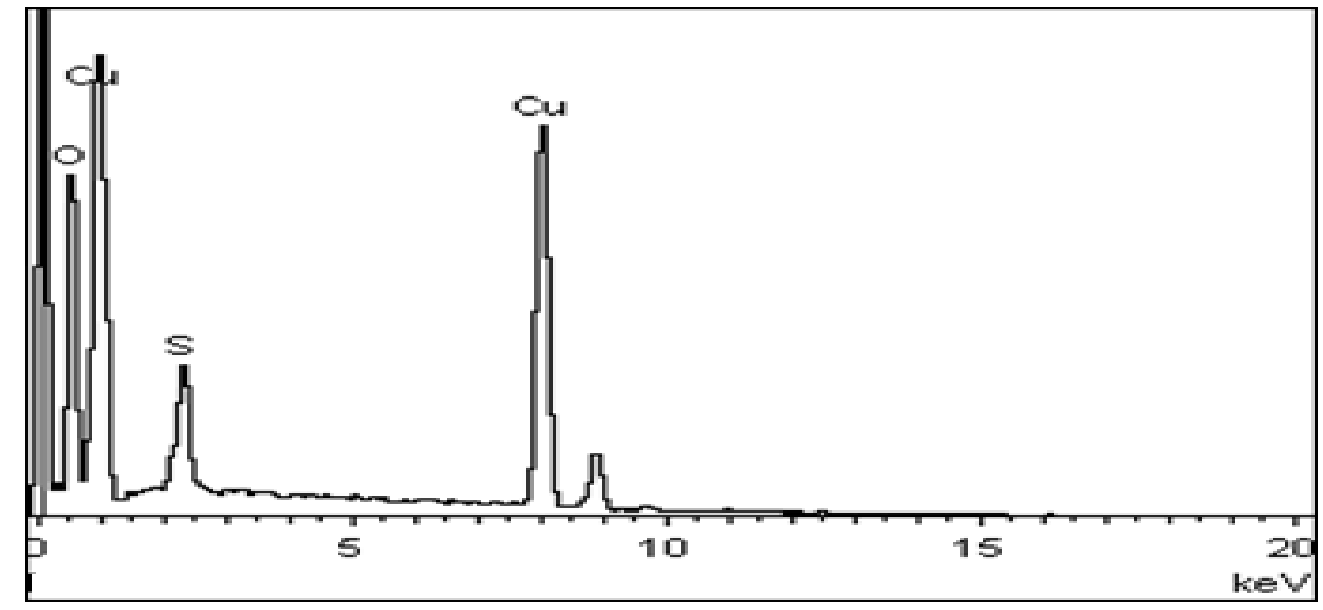

Fig.-4: EDX spectra of $\mathrm{CuO}$ nanoparticles

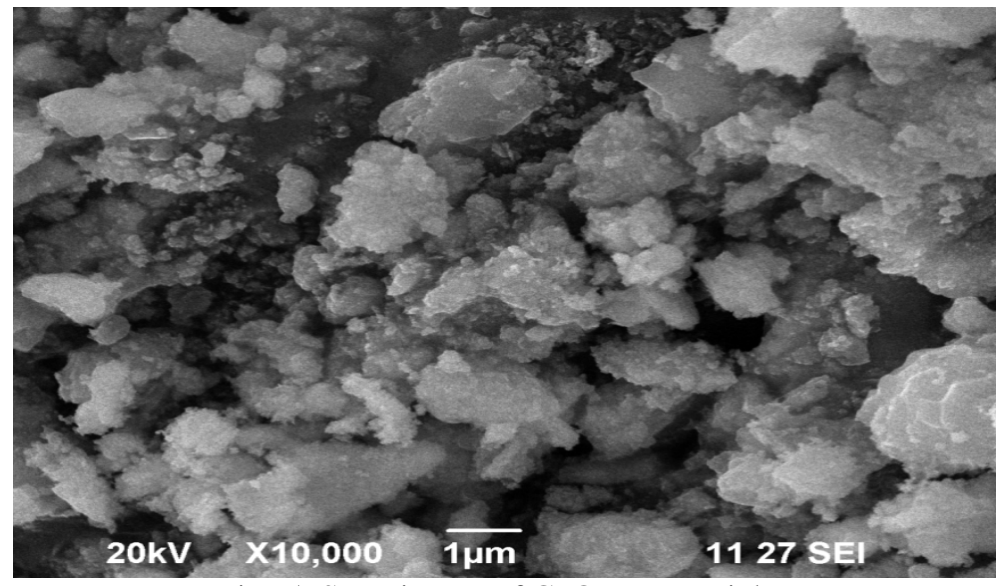

Fig.-5: SEM image of $\mathrm{CuO}$ nanoparticles 


\section{Antibacterial activity of $\mathrm{CuO}$ nanoparticles}

The antibacterial activities of the synthesized $\mathrm{CuO}$ nanoparticles were shown in the Fig.-6. The results show highest inhibition zone for the bacteria Klebsiella pneumonia and the lowest inhibition zone for Staphylococcus aureus. It was observed that, the antibacterial activity was moderate in Streptococcus pneumonia. The results of this study were found to be almost equivalent with that of tetracycline. The inhibition of microorganism's growth using nanoparticles of 6 metal oxides $\left(\mathrm{CuO}, \mathrm{TiO}_{2}, \mathrm{MgO}, \mathrm{CeO}_{2}\right.$, $\mathrm{ZnO}$, and $\mathrm{CaO}$ ) was reported in the literature. The studies indicated that metal oxide nanoparticles display remarkable inhibition on growth of pathogenic bacteria in a size-dependent method in the usual lighting environment. ${ }^{21}$ Raghupathi et al. elucidated that there was an inverse relationship between antibacterial activity and size of the nanoparticles. ${ }^{22}$

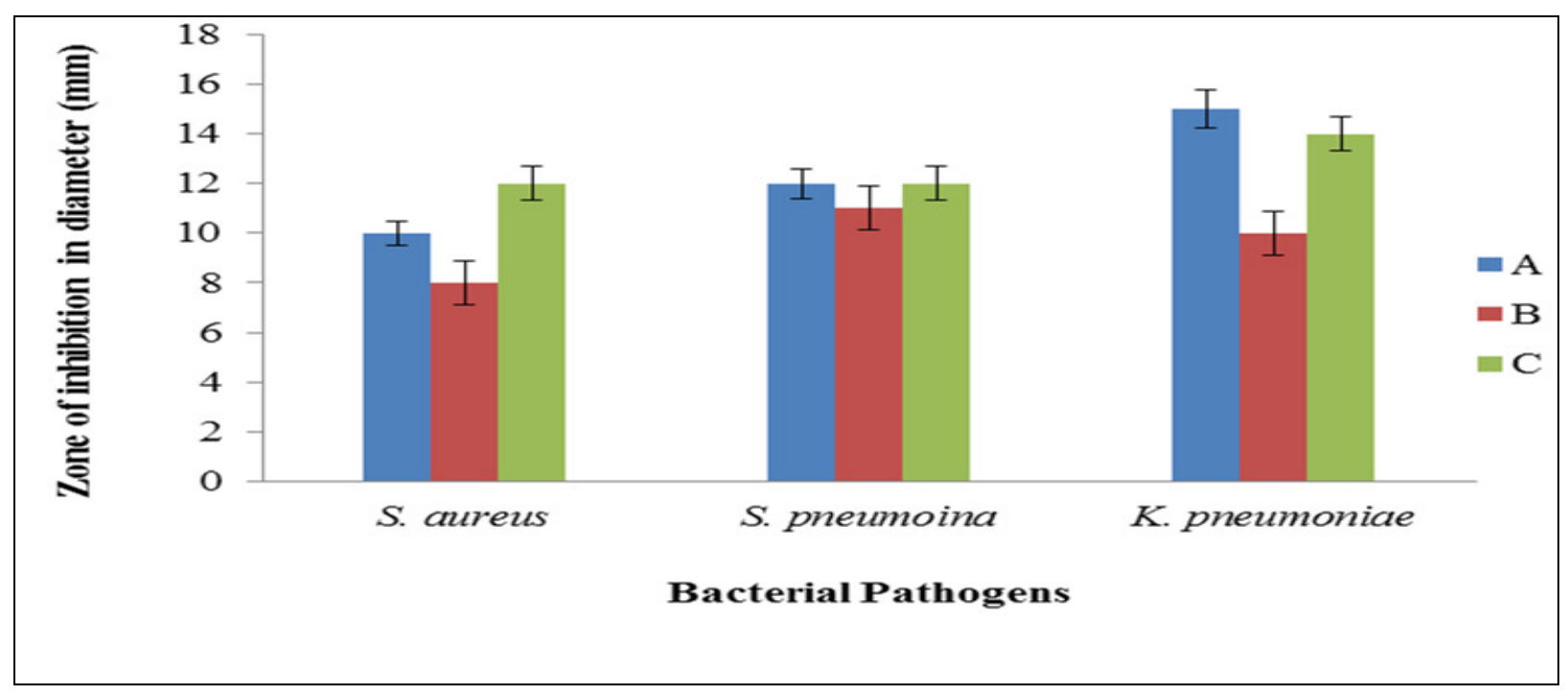

Fig.-6: Antibacterial activities of $\mathrm{CuO}$ nanoparticles (A- $25 \mu \mathrm{g} / \mathrm{ml}, \mathrm{B}-50 \mu \mathrm{g} / \mathrm{ml}$ and C-tetracycline).

\section{CONCLUSION}

Synthesis of $\mathrm{CuO}$ nanoparticles in a simple, eco-friendly and efficient method from Eichhornia crassipes leaf extract using $\mathrm{NaOH}$ was reported in the current work. Aqueous extract of Eichhornia crassipes leaves has been used as reducing agent and also as a capping agent in the $\mathrm{CuO}$ nanoparticle synthesis. $\mathrm{NaOH}$ enhances the formation of $\mathrm{CuO}$ nanoparticles. Antibacterial activity of green synthesized $\mathrm{CuO}$ nanoparticles was performed. The $\mathrm{CuO}$ nanoparticles showed the highest inhibition at lowest concentration against pathogenic bacteria.

\section{REFERENCES}

1. (a.)Renu Sankar, Perumal Manikandan, Viswanathan Malarvizhi, Tajudeennasrin Fathima, Kanchi Subramanian Shivashangari, Vilwanathan Ravikumar, Spectrochimica Acta Part A: Molecular and Biomolecular Spectroscopy, 121,746(2014); (b.) Haritha Meruvu, Meena Vangalapati , Seema Chaitanya Chippada and Srinivasa Rao Bammidi, Rasayan Journal of Chemistry, 4, 217(2011).

2. M. C. Daniel and D. Astruc, Chem. Rev., 104, 293(2004).

3. K. Bogunia-Kubik and M. Sugisaka, BioSystems, 65, 123(2002).

4. V. P. Zharov, J.-W. Kim, D. T. Curiel and M. Everts, Nanomed.: Nanotechnol., Biol. Med., 1, 326 (2005).

5. S. S. Shankar, A. Rai, B. Ankamwar, A. Singh, A. Ahmad and M. Sastry, Nat. Mater., 3, 482(2004).

6. (a.) B. Ankamwar, C. Damle, A. Ahmad and M. Sastry, J. Nanosci. Nanotechnol., 5, 1665(2005); (b.)Varahalarao Vadlapudi , Mohan Behara and M.Nagalakshmi Devamma, Rasayan Journal of Chemistry, 7, 219(2014). 
RASĀYAN J. Chem.

Vol. 10 | No. 3 |838 - 843 | July - September | 2017

7. R Sivaraj, P.K.S.M. Rahman, P. Rajiv, S. Narendhran, R. Venkatesh, Spectrochimica Acta Part A: Molecular and Biomolecular Spectroscopy, 129, 255 (2014).

8. O. Akhavan, E. Ghaderi, Surface and Coatings Technology., 205, 219 (2010).

9. M.S. Hassan, T. Amna, O.B. Yang, M.H. E1-Newehy, S.S. Al-Deyab, Colloids Surf B: Biointerfaces, 97, 201 (2012).

10. P.K. Stoimenov, R.L. Klinger, R.L. Marchin, K.J. Klabunde, Langmuir, 18, 6679 (2002).

11. T. Premkumar, K.E. Geckeler, Small. 2, 616 (2006).

12. G. Ren, D. Hu, E.W. Cheng, M.A. Vargas-Reus, P. Reip, R.P. Allaker, Int J Antimicrob Agents., 33, 587 (2009).

13. C.T. Hsieh, J.M. Chen, H.H. Lin, H.C. Shih, Appl Phys Lett., 82, 3316 (2003).

14. X. Zhang, G. Wang, X. Liu X, J Phys Chem C, 112, 16845 (2008).

15. P. Vanathi, P. Rajiv, S. Narendhran, Sivaraj Rajeshwari, Pattanathu K.S.M Rahman, Rajendran Venckatesh, Mater Lett, 134, 13(2014).

16. W. Bauer, W.M. Kirby, J.C. Sherris, and M. Turck, Am. J. Clin. Pathol. 45, 493 (1966).

17. D. Das, B.C. Nath, P. Phukon, S.K. Dolui, Colloid. Surf. B Biointerface. 101, 430 (2013).

18. Y. Zhao, J.J. Zhu, J.M. Hong, N. Bian, H.Y. Chen, Eur J Inorg Chem, 20, 4072 (2004).

19. A. L. Patterson, Physical Review, 56, 978 (1939).

20. S. Gunalan, R. Sivaraj and R. Venckatesh, Spectrochim. Acta A: Mol. Biomol.Spectrosc., 97, 1140 (2012).

21. N. Jones, B. Ray, R.T. Koodali and A.C. Manna, FEMS Microbiol. Lett. 279, 71 (2008).

22. K.R. Raghupathi, R.T. Koodali and A.C. Manna, Langmuir, 27, 4020 (2011).

[RJC-1800/2017] 